\title{
THE GROWTH OF OUR GIRAFFES AND GIRAFFE.CALVES
}

\author{
BY \\ AXEL REVENTLOW \\ Director Zoological Gardens, Copenhagen
}

As far as I can recollect, only few reliable informations have been published concerning the total height and weight of new-born giraffe-calves; and as constant measuring of the growth of giraffes probably only in very few cases has been undertaken, I should like, by the following article, to contribute a little to the clearing of these matters. My opservations were made from March, 1939, until December, 1948, on Io different giraffes whom I had the opportunity of studying at close quarters here in the Zoological Gardens of Copenhagen.

On October 24th, 19I5, we got a still-born giraffe-calf with a weight of $67,5 \mathrm{~kg}$, the height unfortunately was not recorded.

From 1923 until March, 1939, we had no giraffes in the Garden, and naturally $I$ therefore took the greatest interest in three young giraffes, which I acquired for the garden on March 10, 1939. The animals were caught when quite young in 1937 in Kenya and were in 1938 transported by ship from Mombasa to Germany.

The bull (Bøje) and one of the cows (Lise) were Rothschild- or Baringogiraffes (Giraffa camelopardalis rothschildi Lyd.), the other cow (Else) on the contrary was a Reticulated-giraffe (Giraffa camelopardalis reticu'ata Winton).

Two of these beautiful animals were a gift to us from the chairman of our board, the big-game hunter, Dr. sc. Bøje Benzon.

The total heights of the giraffes were as follows:

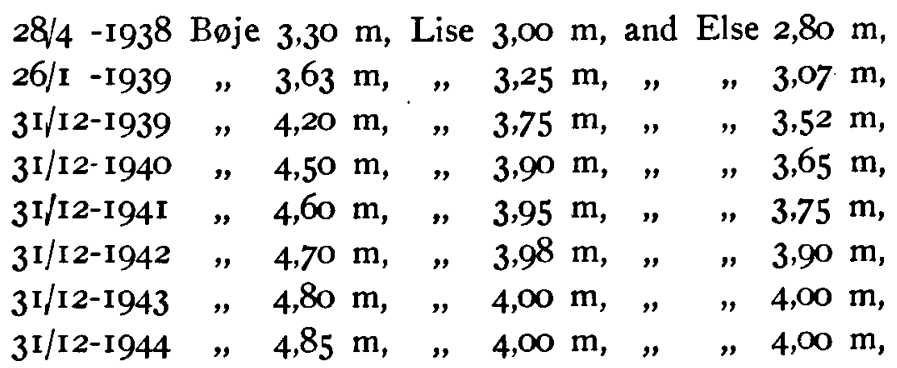

and herewith the animals were full-grown. 


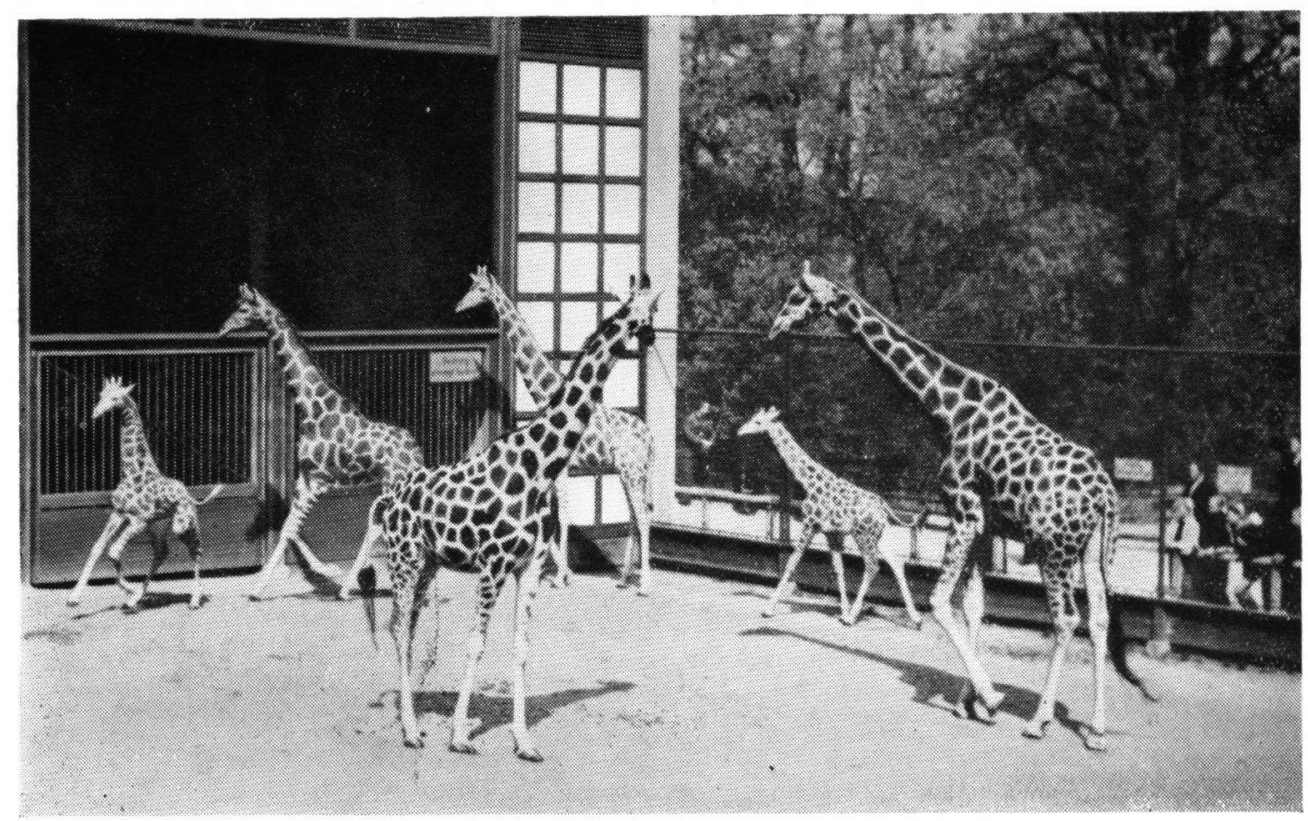

Phot. Alex Reventlow

The whole Giraffe-Family (Bøje, Lise, Else, Grete, Fao, Unrra), Zool. Gardens, Copenhagen 


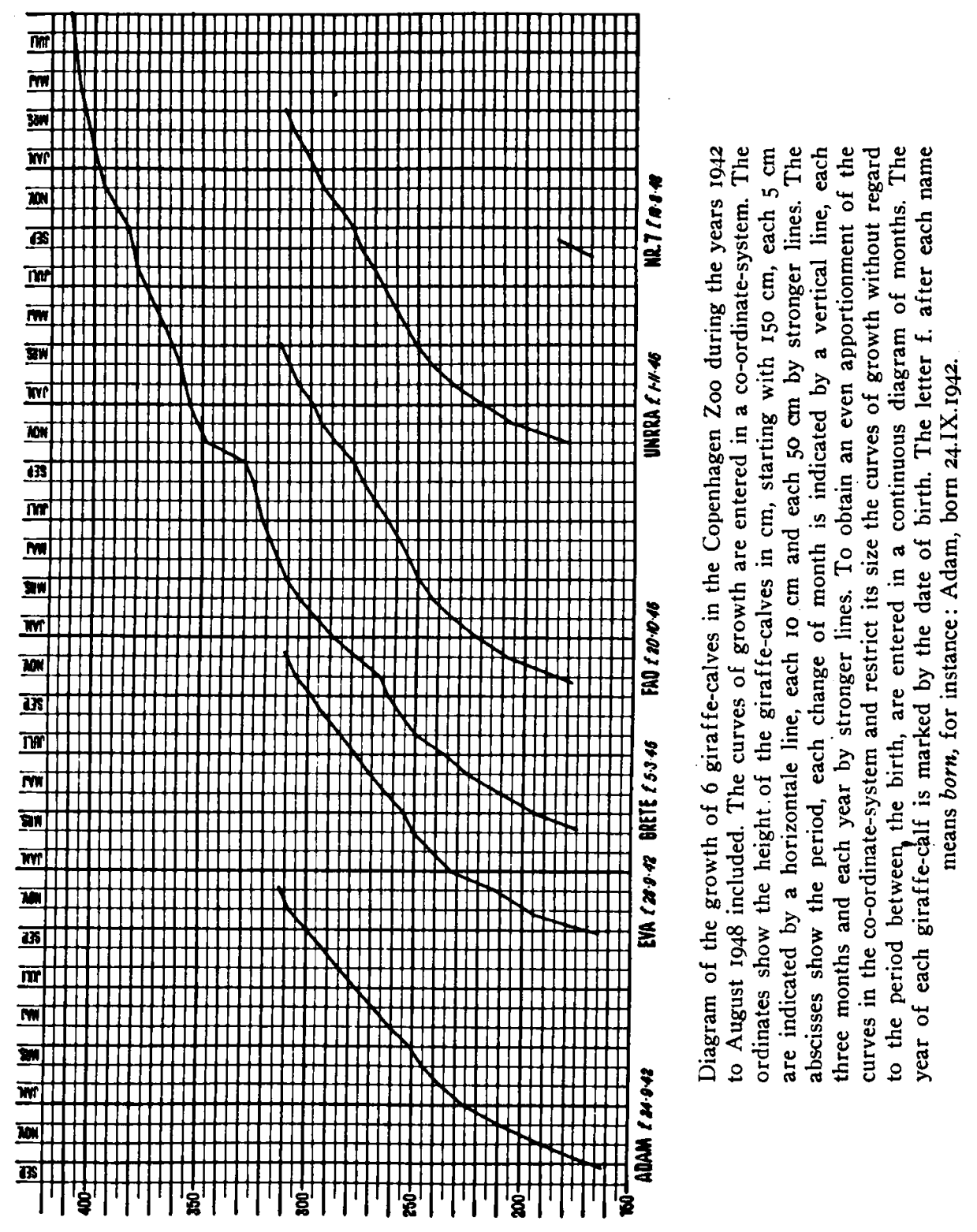


Lise has up to now had 3 calves who at birth had more or less distinct darkbrown patches. Two of these calves, the females Eva and Unrra, grew up and gradually got black spots like the typical Baringo-giraffes. Both of them were sold. The third calf of hers (it did not get any name) was a bull-calf, born on the 21.4.1945. At birth he got a squeeze (trauma) of the pelvis-bone and in consequence of this he was not able to stand on his legs. He died three days later. The height was $1,85 \mathrm{~m}$ and the weight $53,5 \mathrm{~kg}$. At present, Lise is again with young, and we are hoping for a good result.

Else has so far given birth to four calves, three males and one female, Adam, Grete, Fao and no. 7. Adam and Fao were sold, and Grete is still here. She measured on the 31.12.1948 4,12 m. No. 7, born on the 18.8.1948, was despite the fact that the mother during the whole period of gestation had got plenty of sun, fresh air and vitamins a little weak from birth. Else took no interest whatever in this calf; she did not even lick it dry and would not allow it to suck. We tried to give her a petuitrin injection, but as she would not stand still, it proved to be quite impossible. Thereupon we tried to rear the calf with fresh milk from a Jersey-cow, procured exclusively for this purpose. The result, however, was unsatisfactory, both front-legs becoming -swollen and stiff in the knee-joints. After having consulted the chief veterinary surgeon, Mr. A. JACobSen, from the Royal Veterinary School in Copenhagen who shortly after its birth had treated the calf with Calciferol and Hepsol, we decided to shoot it. At birth the height was $1,70 \mathrm{~m}, 47$ days later it was $\mathrm{I}, 82 \mathrm{~m}$ and the weight $64 \mathrm{~kg}$.

Even though the father was a typical dark, almost blackspotted Baringogiraffe, all the calves by Else had more or less distinct light-brown spots, which gradually turned dark-brown and remained so.

The period of gestation has by our giraffes always been very near $14 \frac{1}{2}$ months. Else mated generally only once, whereas Lise always mated several times before becoming with calf.

The diagram on p. 395 shows the growth of our giraffe-calves. It is to be seen, that the ascent of the curves is very irregular, rising especially during the month immediately after the birth and during the months of autumn and early winter.

March, 1949. 